\title{
17th International Symposium on Separation Sciences. News and Beauty in Separation Sciences
}

\author{
Virginia Coman
}

Published online: 31 July 2012

(C) Springer-Verlag 2012

This special issue of Chromatographia contains the papers presented at the 17th International Symposium on Separation Sciences, News and Beauty in Separation Sciences (17th ISSS) held in Cluj-Napoca, Romania on September 5-9, 2011. This international symposium was a scientific meeting organized annually after 2002 by the member countries of the Central European Group for Separation Sciences (CEGSS). This year, the 18th ISSS is being held in conjunction with the 29th ISC in Torun, Poland, and next year, the 19th ISSS will take place in Croatia.

The origin of the ISSS series (not to be confused with the EuSSS) dates back to a GC meetings held in Zagreb in 1967. From 1990, these meetings were organized biennially in Bled (Slovenia) and in Opatija (Croatia) until 1998. During the 4th ISSS in October 1996, it was decided to extend scientific cooperation by inviting societies from Bosnia and Herzegovina, Hungary and Slovakia to participate. Currently, ten countries including Austria, Bosnia, Croatia, Czech Republic, Hungary, Italy, Romania, Slovakia, Slovenia, and Ukraine are members of the CEGSS. The 17th ISSS was the first symposium of this series of meetings to be held in Romania. The symposium was organized by the Cluj Branch of the Romanian Chemical Society (SChR), under the auspices of the SChR, the CEGSS, the EuSSS, the Babeş-Bolyai University from Cluj-Napoca (BBU) and the Romanian National Authority for Scientific Research (ANCS) (Fig. 1).

V. Coman $(\bowtie)$

Babes-Bolyai University,

Raluca Ripan Institute for Research in Chemistry,

30 Fantanele Street, 400294 Cluj-Napoca, Romania

e-mail: coman_virginia@yahoo.com
As a preliminary to this symposium in 4-5 September 2011, the Second Meeting of the "Transylvania Summer School in Chromatography" (tssc'2011) entitled "Past, Present and Future in Chromatography" was organized where Professors Boguslaw Buszewski, Attila Felinger, Pavel Jandera, Jozef Lehotay and Hartmut Frank gave tutorials about fundamentals, practices and ethics in separation sciences. The Summer School was very useful for young scientists to enrich their knowledge about the current progress in chromatography and related separation techniques. It also gave them the opportunity to establish new contacts with their colleagues from other locations. The tssc'2011 participants were allowed to attend the 17 th ISSS scientific programme and exhibitions.

The 17th ISSS was focused on the fundamental and practical aspects of separation and detection methods, sample preparation and hyphenated techniques applied to analytical, preparative and industrial purposes. The symposium allowed scientists from academia and industry from around the world to present their latest results and to establish new collaborations. I wish to offer special thanks to all the people who submitted abstracts covering many areas of separation sciences in chemistry, biology, pharmacy, medicine, environment, ecology, food and life science.

The opening ceremony started with a welcoming address by the symposium chair followed by Professor Florin Stamatian, the prefect of Cluj County, Professor Buszewski, the president of the EuSSS and Professor Victor Corneliu Radu, the vice president of the SChR (Fig. 2). The opening ceremony continued with a talk by Professor Alexandru Simon from the Centre for Transylvania Studies on "Cluj-Napoca, Transylvania's Treasure City". The opening concluded with a performance of folk dances by a company from the Children's Palace. 


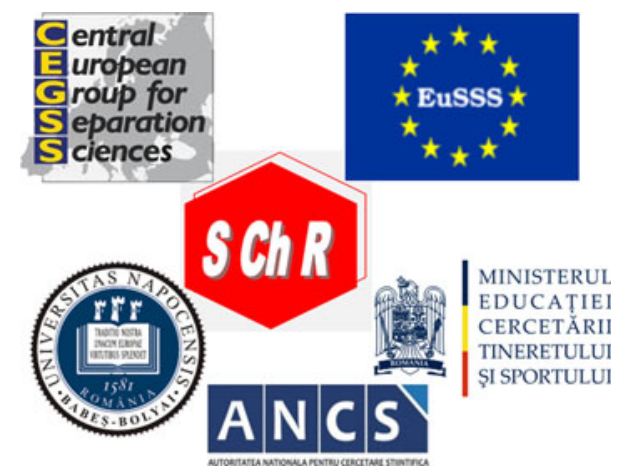

Fig. 1 The organizers of the 17th ISSS symposium

There then followed a lecture "Separation Sciences in Cluj. In Memoriam of Candin Liteanu" presented by the symposium chair. In recognition of Professor Candin Liteanu's (1914-1990) contribution to modern analytical chemistry in Romania, especially to separation science, the 17th ISSS organizing committee introduced and awarded a commemorative medal to his first $\mathrm{PhD}$ Student, Professor Simion Gocan, for his contributions to the development and the promotion of separation sciences in Romania (see in Fig. 3). The Organizing Committee also invited Professor Liteanu's family to this ceremony and presented his son and our colleague, Victor Liteanu, with the medal.

The 17th ISSS Symposium was attended by 212 registered delegates from 18 countries from the UK, Austria, Belgium, Czech Republic, Croatia, France, Georgia, Germany, Iran, Israel, Italy, Japan, Moldova, Poland, Slovakia, Slovenia, Hungary and Ukraine and 138 from Romania.

The scientific programme included 32 plenary lectures (29 from abroad, Fig. 2), 19 oral and 7 podium poster communications and 52 poster presentations. The 17th ISSS participants had the opportunity for discussions with the exhibitors to make the transfer of theory to practice and vice versa.

The winner of CEGSS award at the 16th ISSS in Rome, Kieu Thi Ngoc Nguyen, PhD Student at the University of Genoa, Italy, participated at the symposium with a podium poster presentation. During the closing ceremony, the eight best posters presented by young scientists were granted with the "17th ISSS Best Poster Award". Chromatographia offered three awards, each consisting of one free on-line 2012 subscription, that were won by Vesna Glavnik, PhD Student, National Institute of Chemistry, Ljubljana,
Slovenia; Monika Janicka, PhD Student, Gdańsk University of Technology, Poland; and Veronika Skerikova, PhD, University of Pardubice, Czech Republic. Taylor \& Francis Publishing House donated Ewelina Dziubakiewicz, PhD Student, Nicolaus Copernicus University, Torun, Poland, and Mihaela Vlassa, PhD Student, Babeş-Bolyai University, Raluca Ripan Institute for Research in Chemistry, ClujNapoca, Romania, books and the journal of Toxicological and Environmental Chemistry. These awards were presented by Professor Frank, the Editor-in-chief of the journal at that time.

Three awards consisting free registration and accommodation at the 18th ISSS Symposium in Torun were given by Professor Buszewski, the president of CEGSS, EuSSS and the Polish Chemical Society to a PhD Student from Hungary (Anita Aranyi, University of Szeged) and two $\mathrm{PhD}$ from Cluj-Napoca, Romania (Ede Bodoki, University of Medicine and Pharmacy, and Miuta Filip, BBU). At the gala dinner, awards were made to Professors Danilo Corradini and Corrado Sarzanini for their promotion of the separation sciences through the CEGSS. At the same time, the Candin Liteanu Medal and Diploma was awarded to Professors Engelhardt, Jandera, Tyihák, Frank and Buszewski (Fig. 3).

Some of the papers presented at the 17th ISSS are published in the special issues of Chromatographia (September issue/2012) and of Journal of Planar Chromatography (issue 6/2012), and others have been published in Studia Universitatis Babeş-Bolyai, Chemia, issue $4 / 2011$.

An attractive social programme (Fig. 4) was organized to give the participants the chance to discover the city and the surroundings. The visit to the Turda salt mine was one of the highlights of the social programme. A splendid concert of string instruments was performed by a young quintet in the special concert hall situated in the underground of the salt mine. The participants also had the occasion to enjoy the picturesque landscape of the Gilău Mountains and Tarniţa Lake at sunset and at night at a bonfire and to taste traditional dishes.

I am grateful to all those who made possible the organization of the 17th ISSS symposium, to ANCS, BBU, CEGSS, EuSSS, SChR, and to all sponsors and exhibitors for providing financial, scientific and moral support and also to the members of the organizing and scientific committees, for their efforts in promoting and organizing this event. I also wish to thank Editors and the Editorial Office of Chromatographia for their helpful contributions in 


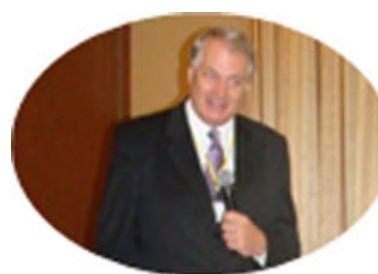

Imre Klebovich

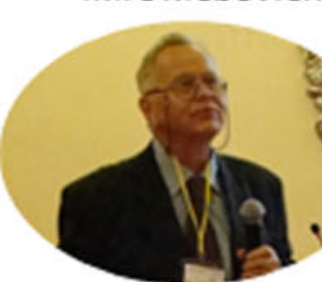

Pavel Jandera

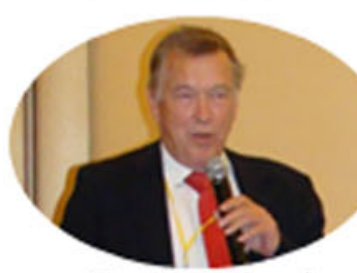

Hartmut Frank

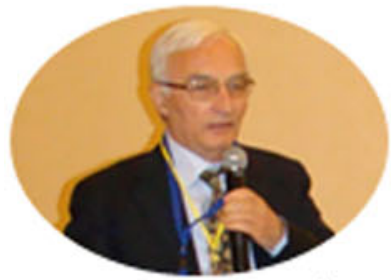

Francesco Dondi

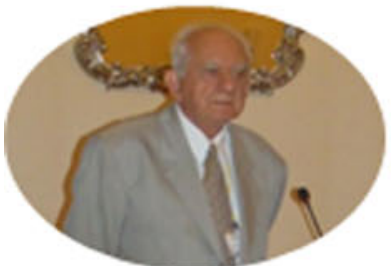

ErnỗTyihák

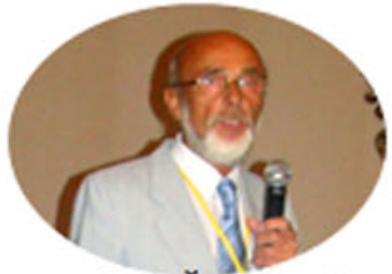

Nikola Šegudović

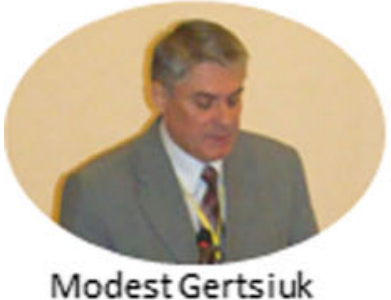

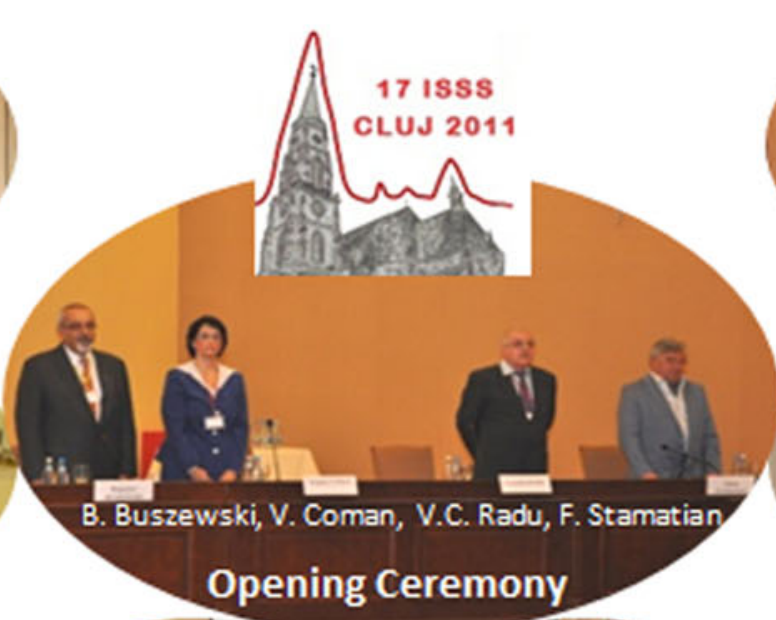

Opening Ceremony
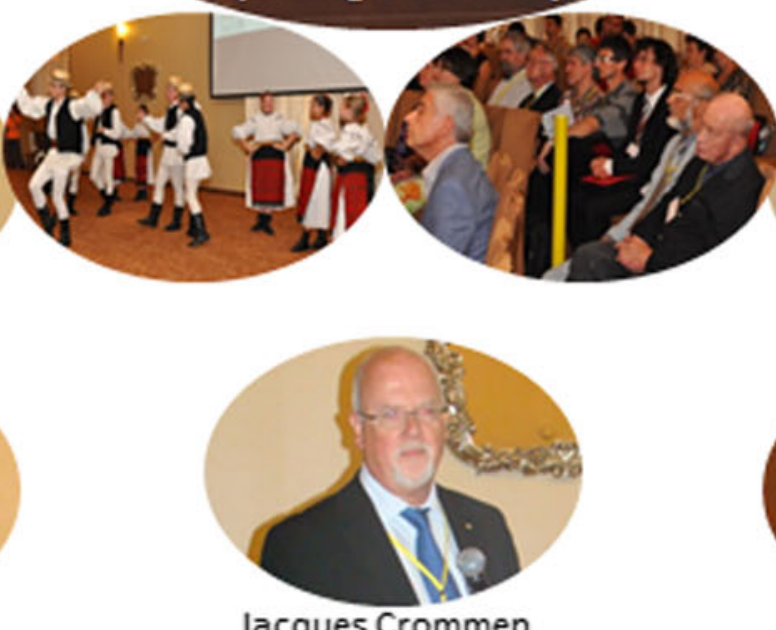

Jacques Crommen
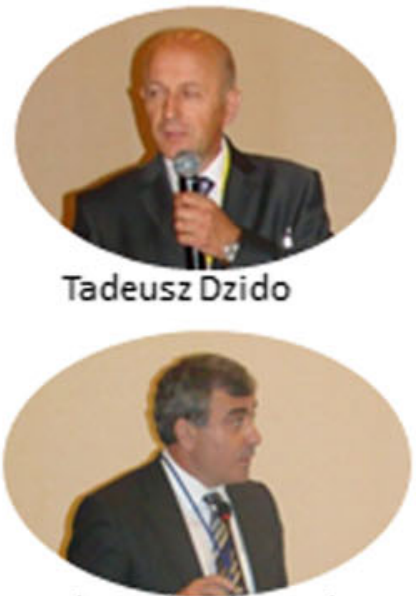

Bezhan Chankvetadze

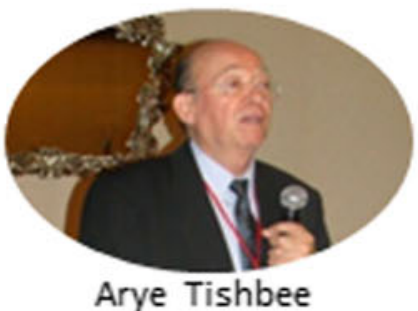

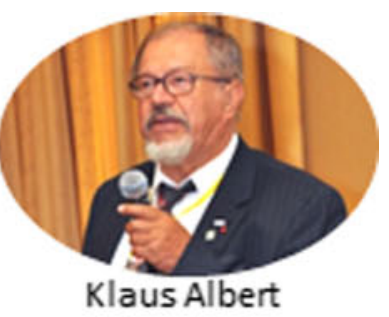

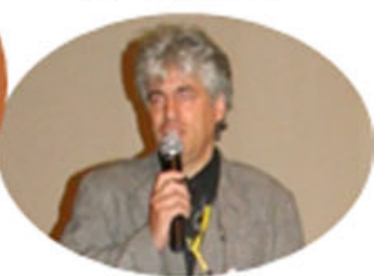

Didier Thiébaut

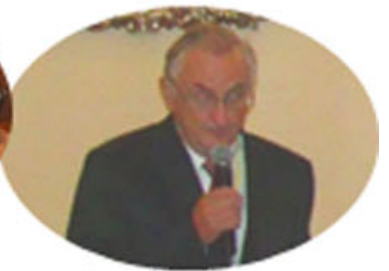

Jozef Lehotay
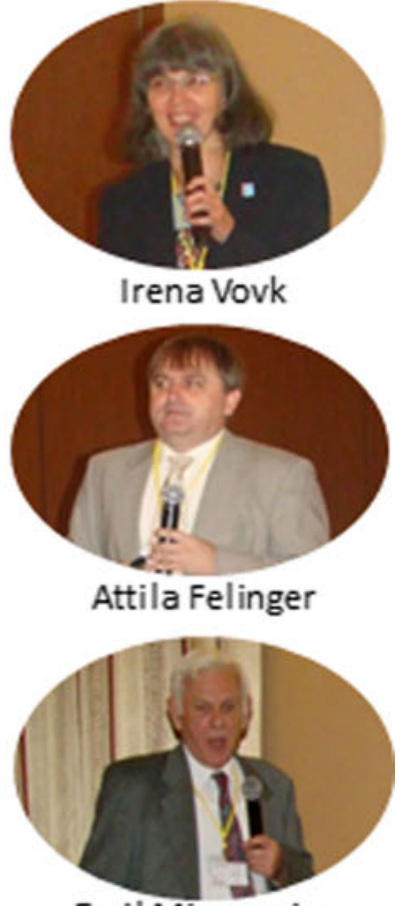

Emil Mincsovics

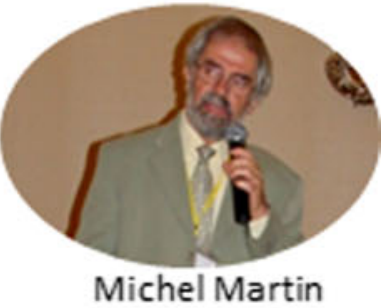

Fig. 2 Some aspects from the opening ceremony and plenary lectures of the 17th ISSS 


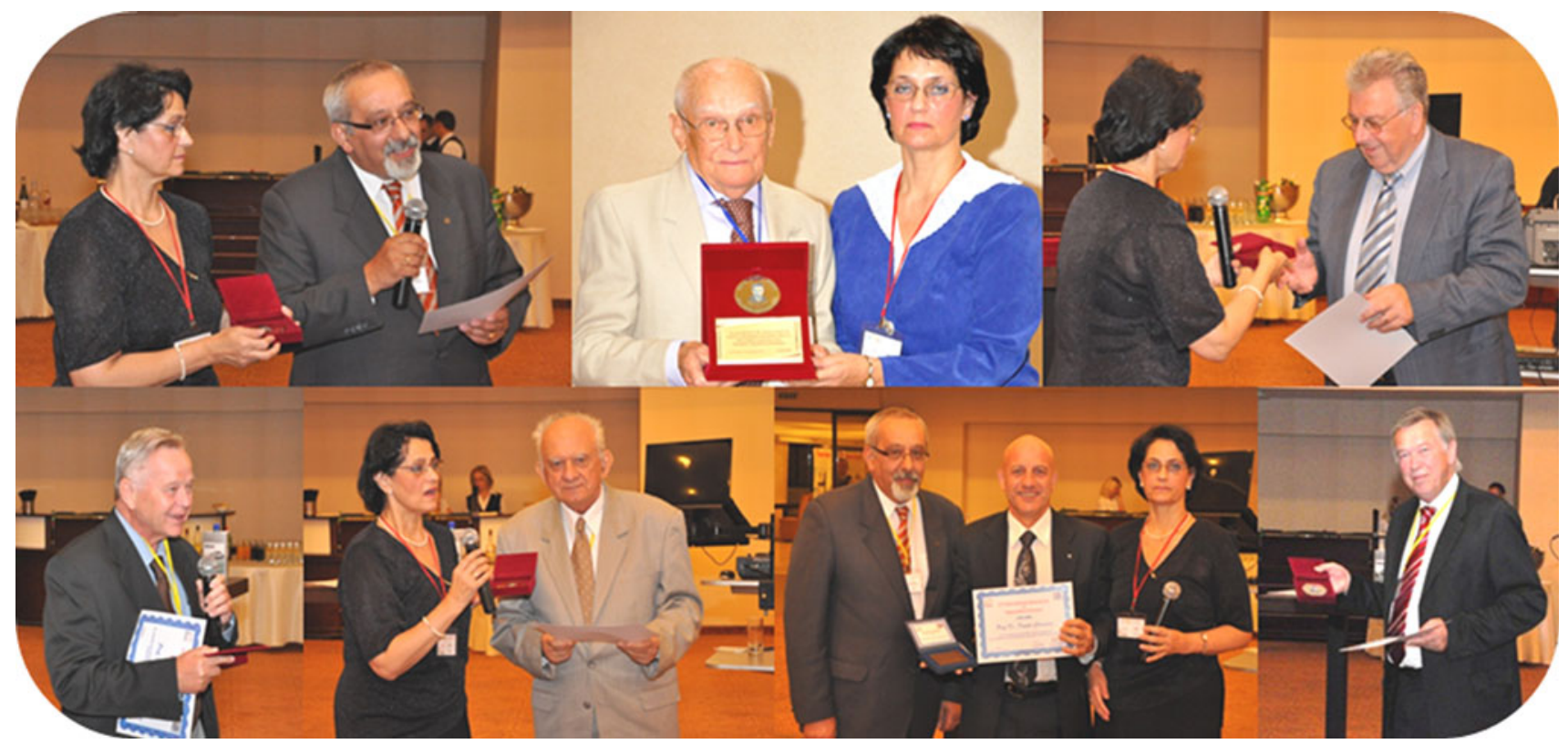

Fig. 3 The personalities awarded with Candin Liteanu Medal. From upper left, Boguslaw Buszewski, Simion Gocan, Heinz Engelhardt, Pavel Jandera, Ernő Tyihák, Danilo Corradini (CEEGS award), Hartmut Frank, and 17th ISSS chair Virginia Coman

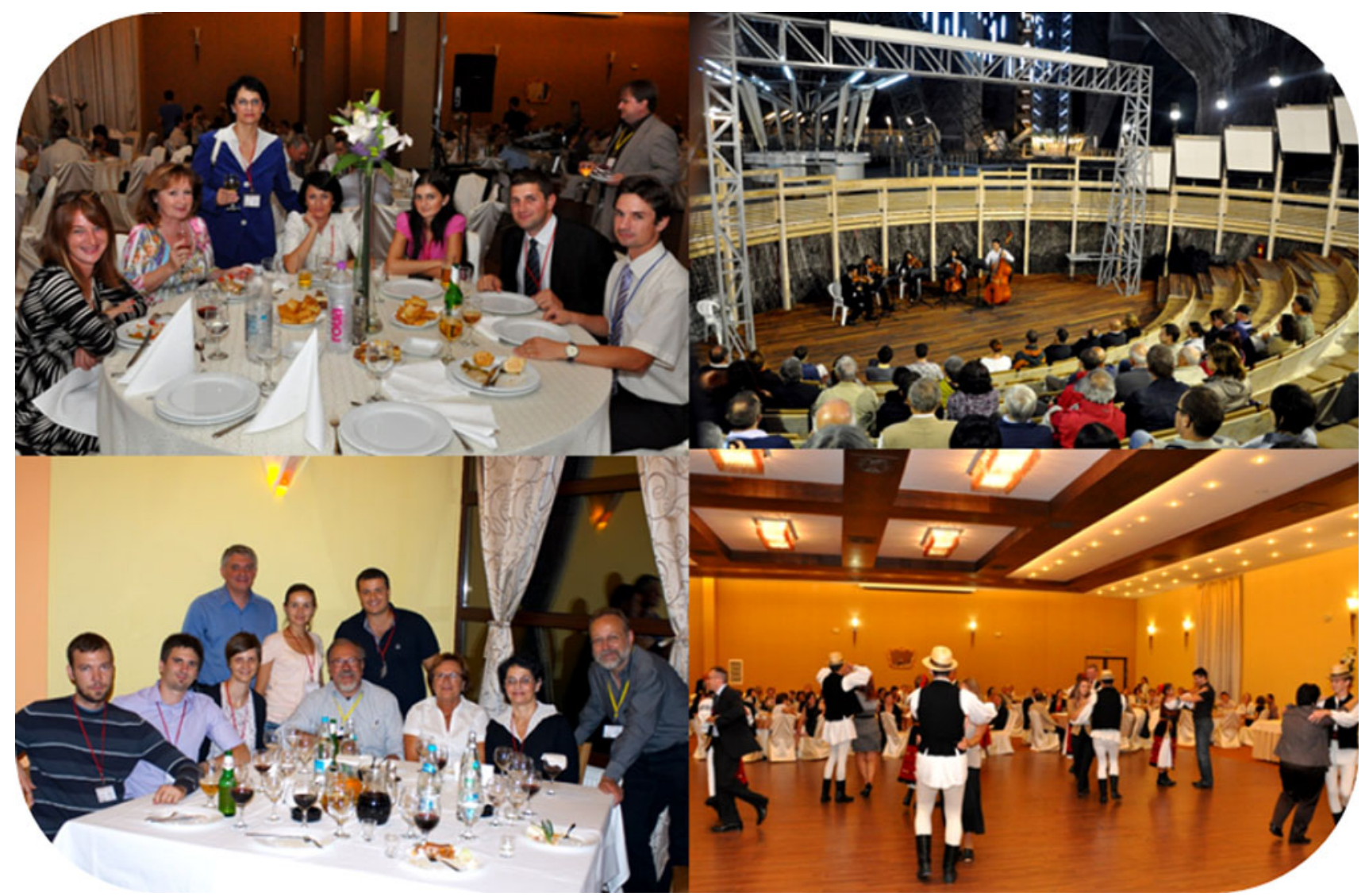

Fig. 4 Aspects from the social programme from upper left: welcome reception, string concert in Turda salt mine, grill party, gala dinner 
publishing this special issue. Finally, I would like to express the gratitude of the organizers to all invited speakers, lecturers and participants who attended the 17th
ISSS and presented their research results. I hope that during the symposium new opportunities for fruitful collaborations and new ideas for further advances appeared.

Virginie Coman Virginia Coman Chair of 17th ISSS 